\title{
RETRACTED ARTICLE: Spatio-temporal variability of soil moisture-precipitation feedback in Indian summer monsoon regime
}

\author{
Abhishek Lodh • Ramesh Raghava
}

Received: 18 July 2013 / Accepted: 22 January 2014 /Published online: 13 February 2014

(C) Springer-Verlag Wien 2014

The Editor and The Publisher have retracted this article due to self-plagiarism. The same authors published in the Journal Vayu Mandal (Bulletin of the Indian Meteorological Society) Abhishek Lodh and Ramesh Raghava (2012) Soil moisture precipitation feedback on Indian climatic zones in Indian summer monsoon regime, 38:3-4, pp 46-55, unknown to both the Editor and the reviewers of Theor. Appl. Climatol., incorporating text and figures of a similar nature and no citation to that earlier work.

\footnotetext{
A. Lodh $(\bowtie) \cdot$ R. Raghava

Centre for Atmospheric Sciences, Indian Institute of Technology

Delhi, Hauz Khas, New Delhi 110016, India

e-mail: abhishek.lodh@gmail.com
} 